\title{
VALERIANA OFFICINALIS: A REVIEW OF ITS TRADITIONAL USES, PHYTOCHEMISTRY AND PHARMACOLOGY
}

\author{
SUNDARESAN NANDHINI ${ }^{1}$, KASTHURI BAI NARAYANAN ${ }^{1}$, KALIAPPAN ILANG0 ${ }^{1,2 *}$ \\ ${ }^{1}$ Pharmacognosy and Phytochemistry Division, Interdisciplinary Institute of Indian System of Medicine, SRM University, \\ Kattankulathur- 603 203, Kancheepuram (DT), Tamil Nadu, India. ${ }^{2}$ Department of Pharmaceutical Chemistry, SRM College of Pharmacy, \\ SRM University, Kattankulathur- 603 203, Kancheepuram (DT), Tamil Nadu, India. Email: ilangok67@gmail.com
}

Received: 15 September 2017, Revised and Accepted: 23 October 2017

ABSTRACT

Valeriana is a well-known Indian traditional medicinal herb with sleep remedy. It has been used over the years to treat nervine and sedative in hysteria, epilepsy, and sedative in nervous anxiety. It has also been used as an aromatic stimulant and reported some distinctive indications, as well as its use for rheumatism, low-grade fevers, and aphrodisiac. It has been known to grow well in regions of Europe, parts of Asia and North America. This systematic review focuses on the ethnopharmacological uses of Valeriana, including recent advances on the phytochemical and pharmacological study of Valeriana officinalis. In addition, future developments and scenarios in the study of the plant have been proposed. Various literature and electronic databases such as PubMed, ScienceDirect, Springer, and Wiley were searched and data obtained. Other online academic libraries such as Google Scholar and ethnopharmacological literature were searched systematically for more information on the plant. In this paper, we have reviewed various research conducted on $V$. officinalis especially in areas of its ethnopharmacological use, phytochemicals, and pharmacology. This plant has been used medicinally for a minimum of 2000 years. It is used in the treatment of brain disorder and also used for the treatment of varied nervous disorders, antispasmodic, anthelmintic, diuretic, diaphoretic, and emmenagogue, and hysteria. More research is needed in the area of pharmacokinetics and toxicology to give further information on the clinical use and control the quality of the plant.

Keywords: Valeriana officinalis, Ethnomedicine, Phytochemistry, Neuroprotective.

(C) 2018 The Authors. Published by Innovare Academic Sciences Pvt Ltd. This is an open access article under the CC BY license (http://creativecommons. org/licenses/by/4. 0/) DOI: http://dx.doi.org/10.22159/ajpcr.2018.v11i1.22588

\section{INTRODUCTION}

Valeriana is a genus of flowering plants in the Caprifoliaceae family, members of which can be normally called as valerians. The name valerian is derived from Valerius, the Latin term "valere," which means health or well-being [1,2]. Valerian consists of the fragments or whole fresh or dried rhizomes, roots, and stolons. There exist about 200 species in Europe, Asia, and North America. Some of the species are Valeriana officinalis, Valeriana jatamansi, Valeriana wallichii, Valeriana hardwickii, Valeriana microphylla, Valeriana longiflora, and Valeriana quadrangularis, etc. It has been used medicinally for 2000 years. It absolutely was first used as a treatment for brain disorder within the late $16^{\text {th }}$ century. It is habitually used for the treatment of varied nervous disorders [3], antispasmodic, anthelmintic, diuretic, diaphoretic, and emmenagogue, and hysteria. It has an aromatic stimulant and reported some distinctive indications, as well as its use for rheumatism, low-grade fevers, and aphrodisiac, further as its use in hysteria [4]. Valerian is used as a nervine sedative for the treatment of hysteria, epilepsy and sedative in nervous anxiety [5]. It conjointly used as a cerebral stimulant, analgesic and sedative in nervous irritability, specifically once the condition may be a result of "enfeebled cerebral circulation [6]."

Natural products have upper hand over synthetic drugs because they have fewer side effects and also does not alter physiological and biochemical pathways [7]. Over the years, medicinal plants of the Valeriana genus are shown to treat rheumatism, low-grade fevers, aphrodisiac, nervous disorders, spasmolytic, anthelmintic, diuretic, diaphoretic emmenagogue, and additionally to hysteria [8]. However, the traditional uses of these plants have been recorded primarily in local herbal books or have been passed down orally from one generation to other. The medicinal use of the Valerian, compared to its ornamental and food uses, must be investigated further as it is widespread with known therapeutic efficacy. The compounds and extracts from $V$. officinalis have exhibited a broad spectrum of biological and pharmacological activities, including antioxidant, antimicrobial, anti-inflammatory, antirheumatic sedative, anxiolytic, tranquilizing, spasmolytic, anticonvulsant, and neuroprotective activities [9-11].

In this review, an attempt was made to present an overall overview of the ethnopharmacological uses of this Indian traditional medicine, its phytochemical properties and pharmacological activities of V. officinalis, so the gaps and areas requiring further research works of this plant can be highlighted.

\section{V. officinalis}

$V$. officinalis var. latifolia is a perennial herb obtained from the Valeriana genus of the Valerianaceae family found in North America, Europe, and Asia [12]. It is a glabrous or more or less pubescent herb, up to $1.5 \mathrm{~m}$ in height. Rootstocks short, sub-erect, hardly thicker than stem, and stoloniferous; stem stolitary, erect, and furrowed [13]. V. officinalis has pinnately-separated leaves, generally with 6-10 pairs of lance-shaped leaflets and bears numerous small white or pink flowers in a dense head of many stalked clusters. These heads bare small ( $5 \mathrm{~mm}$ ) tapered seeds, almost hairless at maturity (Fig. 1) [13-15].

\section{TAXONOMICAL CLASSIFICATION [16]}

Kingdom: Plantae

Unranked: Angiosperms

Unranked: Eudicots

Unranked: Asterids

Order: Dipsacales

Family: Caprifoliaceae/Valerianaceae

Genus: Valeriana

Species: Officinalis 

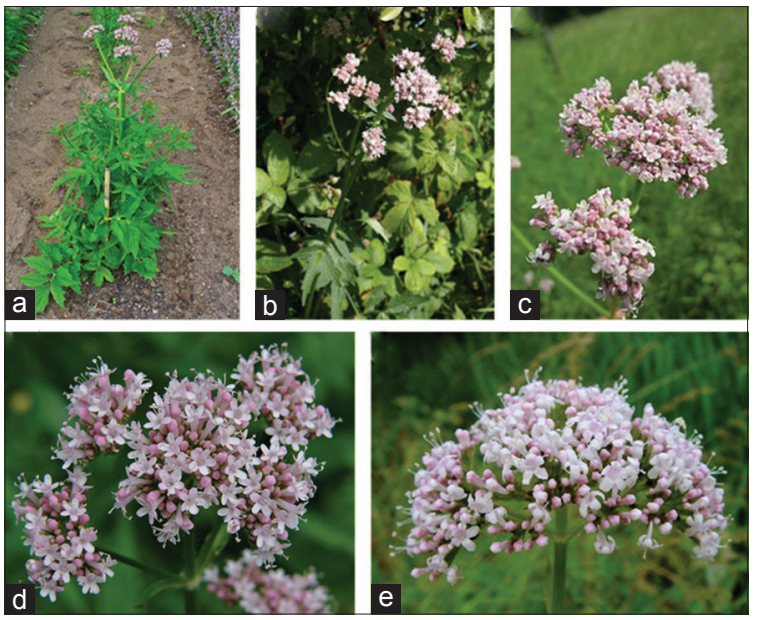

Fig. 1: Morphology of Valeriana officinalis (a) whole plant, (b) aerial parts with flower, (c) flower at an early stage, (d) flower and $(e)$ stem $[16,17]$

Vernacular names [18]

\begin{tabular}{ll}
\hline Arabic & Sanballat Web \\
\hline English & Allheal, English valerian, garden heliotrope, German \\
& valerian, great wild valerian, valerian, vandal root \\
Marathi & Kalavala \\
Sanskrit & Balahrivera \\
Tamil & Catamaci, jatamansi, paicavi, takram \\
Urdu & Balchar, balchhar, bulchar, ikleel-ul-malik, nardin, \\
& sumbul-ut-teeb \\
\hline
\end{tabular}

Common names [19]

English: Valerian, garden heliotrope, common valerian.

Ayurvedic: Tagara, Nata. Baalaka (syn. Udichya, Jala, Barhishtha) is also equated with Valeriana sp.

Folk: Sugandhabaalaa, taggar

\section{CHEMICAL CONSTITUENTS}

It consists of about 150-200 chemical constituents [20,21], as well as flavonoids with activity on the Central nervous system [22] and lignans. Valerenic acid is regarded as the major constituent $[23,24]$. The roots and rhizomes of $V$. officinalis have two main groups of constituents: Sesquiterpenes of the volatile oil (valerenic acid and its other derivatives, valeranone, valeranal, and kessyl esters) and valepotriates (valtrate, didrovaltrate, acevaltrate, and isovaleroxyhydroxyvaltrate), an extension to other constituents such as flavonoids, triterpenes, lignans, and alkaloids [25-28]. A wide range of sesquiterpenoids have been discovered from $V$. officinalis including volvalerenals A-F, volvalerenic acids A-D, volvalerelactones A-B, and valeneomerins A-D [29-31].

\section{Traditional uses}

In traditional herbal medicine, the roots of $V$. officinalis have long been utilized for sedative and antispasmodic purposes [12,32] and can also be used for curing cardiac arrhythmia [33]. Valerian root has been used for a century as a relaxing and sleep-promoting plant [34,35]. It also used to treat hysteria, hypochondriasis, nervous unrest, and similar emotional states. The juice of fresh drug used as a narcotic in insomnia and anticonvulsive in epilepsy [13]. The root has been medically used to treat insomnia and blood, circulatory, and mental disorders [36]. It can also be used to treat digestive problems and urinary tract infections for at least 1,000 years. It is used as sedative, anxiolytic, antidepressant, antispasmodic, and anti-HIV bioactivities [37-41]. In the United States, it is mainly sold as a sleeping aid, while in Europe it is used for restlessness, tremors, and anxiety [12]. In Brazil, it has been used in conventional medicine for its sedative, anticonvulsant, hypnotic effects, and anxiolytic activity [42].

\section{Phytochemistry}

Wangetal.isolated Volvalerine A, a novel N-containingbisesquiterpenoid derivative with a dihydroisoxazole ring and its possible biosynthetic precursor,1-hydroxy-1,11,11-trimethyldecahydrocyclopropane azulene-10-one from the roots of V. officinalis [43]. Han et al. isolated valeneomerins A-D, two unique neomerane-type sesquiterpenoids and two newer nor-sesquiterpenoids from the roots of $V$. officinalis. Their structures were characterized by elaborate spectroscopic analysis and Cu Ka X-ray crystallography [31]. Mirzaei and Dinpanah examined the applicability of hollow fiber-based liquid phase microextraction for the extraction and pre-concentration of valerenic acid earlier to its identification by reversed-phase high-performance liquid chromatography/ultraviolet [44]. Wang et al. isolated volvalerenone A, a new type of mononorsesquiterpenoid with an unprecedented 5/6/6 tricyclic ring system from the roots of $V$. officinalis. A plausible biosynthetic pathway of volvalerenone $A$ was also proposed [45].

Ying et al. documented isolation and structural elucidation of two new molecules such as a new sesquiterpene, orivalerianol $(4 \beta, 10 \alpha$, 15-trihydroxy-aromadrendane) and a new iridoid, monovalerianester A (aglycone of kanokoside A) collectively with eight known compounds rulepidol, behenic acid, pinoresinol, valerenic acid, $\beta$-sitosterol, kanokoside A, prinsepiol-4-O- $\beta$-D-glucoside, and 8-hydroxypinoresinol4-O- $\beta$-D-glucoside were attained from the EtOAc extract and n-BuOH extract [46]. Wills and Shohet studied the dried V. officinalis powdered root on storage at 5,14 , and $30^{\circ} \mathrm{C}$ under low, moderate, and high humidity environment for 6 months and the amount of the valerenic acids analyzed on a monthly basis. The concentration of valerenic acid considerably reduced over time and was impacted by temperature and humidity with the loss the greatest at $30^{\circ} \mathrm{C}$ in low humidity [47]. Safaralie et al. examined the extraction of essential oil from $V$. officinalis roots growing wild in Iran by hydrodistillation and supercritical $\mathrm{CO}_{2}$ extraction. 47 components representing $89.3 \%$ and 35 constituents ranging from $86.1 \%$ to $95.1 \%$ of the oil achieved by hydrodistillation and supercritical $\mathrm{CO}_{2}$ were identified, respectively [48]. Huang et al. evaluated the volatile compounds of the roots of $V$. officinalis utilizing supercritical fluid extraction and headspace solid phase microextraction with gas chromatography-mass spectrometry. The results were compared with those achieved by hydrodistillation. 72 compounds were isolated and identified by gas chromatography-mass spectrometry (GC-MS). The results demonstrated that the major volatile components of $V$. officinalis were completely different from those of $V$. officinalis and diverse with distinctive extraction processes [49].

Hromadkova et al. extracted the insoluble plant residues attained after preparation of medicinal tinctures from the roots of $V$. officinalis by standard and ultrasound-assisted extraction with aqueous ethanol. The net yields of extracted polysaccharides were enhanced in the ultrasound extraction procedure [50]. Paul et al. isolated and determined the sesquiterpenoid constituents of the essential oils from the liverworts Frullania tamarisci, Frullania fragilifolia, and angiosperm of $V$. officinalis. From the study, it was found that the compounds present in both the essential oils of the Frullania species and V. officinalis were enantiomeric to each other [51]. Tori et al. isolated valeracetate, a new guaiane-type sesquiterpene and three previously known sesquiterpenes from $V$. officinalis and their structures were determined by spectroscopic techniques [52]. The composition of the steamdistilled oil from the roots of 9-month-old field-grown $V$. officinalis was analyzed and compared with Agrobacterium-mediated transformed roots of the similar species by Gränicher et al. Capillary GC and GC-MS reports revealed that normal oil comprised of bornyl acetate (13.3\%) and valerenal $(12.4 \%)$ and the transformed oil contained kessane derivatives, tentatively identified as kessyl alcohol (10.5\%), and kessyl acetate $(10.4 \%)$, as the main constituents [53].

Gränicher et al. isolated a new iridoid diester (1R,2S,6S,9S)-5acetyloxymethyl-9-methyl-3-oxabicyclo [4.3.0.] non-4-en-2-yl isovalerate from the hairy roots of $V$. officinalis transformed with Agrobacterium rhizogenes R1601. Five valepotriates were isolated and 
recognized by means of mass spectrometry and ${ }^{1} \mathrm{H}$ and ${ }^{13} \mathrm{C}$ nuclear magnetic resonance (NMR) spectrometry [54]. The difference in terpene composition of the leaf essential oil was determined in three populations of $V$. officinalis by Lokar and Moneghini. The GC-MS analysis was used to establish the composition of the terpene volatile fraction of the essential oil, with the detection of 34 components, 31 of which have been known. The greater variances were stated in the percentages of $\alpha$-pinene, butyl valerate and isobornyl isovalerate among the three populations [55]. Bos et al. isolated seven new valerian sesquiterpenoids from a dichloromethane extract of $V$. officinalis. The NMR, infrared (IR) and mass spectral data of the isolated compounds were achieved [56]. Bos et al. isolated sesquiterpenoid from $V$. officinalis of which the spectral data (IR, NMR, and mass spectra) were in covenant with those of faurinone. They projected a new structure for faurinone based on ${ }^{13} \mathrm{C}$ NMR and ${ }^{1} \mathrm{H}$ NMR shift and decoupling assessments [57].

Hendriks et al. examined the essential oils of some $V$. officinalis populations collected from 29 localities in the northern part of Netherlands. Using GC-MS, two chemovars could be differentiated based on the existence or absence of valeranone. No differences could be shown in the pattern of the valepotriates which were expected to be the most important pharmacologically active constituents of Valerian [58]. Hazelhoff et al. executed an arithmetical correlation between the Soxhlet extraction and the percolation extraction of (iso) valtrate from several Valeriana preparations and it did not show a significant change with respect to their accuracy [59]. Hazelhoff et al. determined the composition of the essential oil of subterranean parts of a commercial Valerian strain. GC-MS was performed, and 69 compounds could be identified of which 45 had not been reported the presence of essential oil of European Valerian. Three types of essential oil were distinguished in a comparative investigation of root material from the number of individual plants of $V$. officinalis, namely: Type A: 2.4$4.9 \%$ elemol, $6.2-8.7 \%$ valeranone, and $3.4-15.9 \%$ valerenal; Type B: 9.8-11.7\% elemol, $0.3-2.0 \%$ valerenal, and no valeranone; Type C: $1.9-$ $2.8 \%$ elemol, $16.2-18.1 \%$ valeranone, $9.3-10.3 \%$ and valerenal [60]. Popov et al. isolated a new valepotriate (VII) from Valeriana officinalis roots and its structure and stereochemistry determined. Comparison with didrovaltrate was made and an alteration of its C-l configuration proposed [61]. Johnson and Waller isolated actinidine alkaloid from dried roots of $V$. officinalis by $\mathrm{CHCl}_{3}-\mathrm{MeOH}$ preceded by an $\mathrm{Et}_{2} \mathrm{O}$ extraction and followed by a $10 \% \mathrm{HCl}$ extraction [62]. Torssell and Wahlberg isolated a crystalline, optically active, quaternary base from the dried roots of $V$. officinalis as the chloride and it was converted to a trifluoroacetate. The structures were revealed by spectroscopic techniques (Fig. 2) [63].

\section{PHARMACOLOGICAL ACTIVITY}

Chen et al. evaluated acetylcholinesterase (AchE) inhibitory activity of isolates, four new sesquiterpenoids and a new monoterpenoid from the root of $V$. officinalis by modified Ellman method in vitro. Learning and memory ability of isolate, volvalerenal acid $\mathrm{K}$ on mice was evaluated by the Morris water maze. Contents of acetylcholine (Ach), acetylcholine transferase (ChAT) and AchE in mice brains were measured by colorimetry. From this study, it was concluded that volvalerenal acid K can improve the learning and memory abilities of APPswe/PSAE9 doubletransgenic mice and the mechanism may be related to the regulation of the relative enzyme in the cholinergic system [64]. Torres-Hernández et al. demonstrated the PTZ challenge in adult zebrafish for potential antiepileptic drugs. Valerenic acid and V. officinalis (both aqueous and ethanolic extracts) increase the latency to PTZ-induced seizure in adult zebrafish in a concentration-dependent manner. The result suggested that Valerenic acid and $V$. officinalis would be possible new therapeutic alternatives for epileptic patients [65]. Nam et al. investigated the effects of $V$. officinalis root extracts and its active constituent, valerenic acid on memory function, cell proliferation, neuroblast differentiation, serum corticosterone, and lipid peroxidation (LPO) in adult and aged mice. The administration of valerian root extract and valerenic acid significantly improved the preferential exploration of new objects in novel object recognition test and the escape latency, swimming speeds, platform crossings, and spatial preference for the target quadrant in Morris water maze test compared to the D-galactose-treated mice. The result concluded that the $V$. officinalis root extract and valerenic acid enhance cognitive function, promote cell proliferation, neuroblast differentiation and reduce serum corticosterone, LPO in aged mice [66].

Shahidi et al. evaluated the effect of hydroalcoholic extract of $V$. officinalis on pain modulation and its possible mechanism in mice. Tail-flick and writhing tests were used for estimation of possible modulation of pain. The tail-flick latencies in the valeriana $800 \mathrm{mg} / \mathrm{kg}$, combined valeriana 800 + naloxone, ondansetron, metoclopramide, or scopolamine-treated groups were significantly longer than that in the control group. The numbers of writhings in the Valeriana $(800 \mathrm{mg} / \mathrm{kg})+$ ondansetron and metoclopramide treated groups were significantly greater than in the extract $(800 \mathrm{mg} / \mathrm{kg})$ group. It was concluded that $V$. officinalis extract possesses a clear analgesic effect and works through the serotonergic and dopaminergic systems [67]. Sudati et al. investigated the potential protective effects of $V$. officinalis against the toxicity induced by rotenone in Drosophila melanogaster. Rotenone-fed flies had a worse performance in the negative geotaxis assay (i.e., climbing capability) and open-field test (i.e., mobility time) as well as a higher incidence of mortality when compared to control group. $V$. officinalis treatment offered protection against these detrimental effects of rotenone [68]. Pereira et al. investigated the possible preventive effects of $V$. officinalis, a medicinal plant widely used to improve disturbances in sleep, against vacuous chewing movements (VCM) in rats [69].

Barton et al. evaluated the efficacy of $V$. officinalis supplement for sleep in people with cancer who were undergoing cancer treatment. A supplemental, exploratory analysis revealed that several fatigue endpoints, as measured by the BFI and POMS, were significantly better for those taking valerian over placebo. Exploratory analyses revealed improvement in some secondary outcomes such as fatigue [70]. The effect of valerian extracts on an experimental model of temporal lobe epilepsy was evaluated by Rezvani et al. The involvement of adenosine system in the actions of aqueous extract of valerian was also evaluated. The results showed the significant anticonvulsant effect for aqueous but not in petroleum ether extract of valerian [71]. Murphy et al. reported behavioral measures of $V$. officinalis and benzodiazepine diazepam and to analyze the chemical composition of $V$. officinalis. Significant reduction of anxious behavior in valerian extracts and valerenic acid exposed subjects when compared to the ethanol control group. This evidence supported $V$. officinalis as a potential alternative to the traditional anxiolytics as measured by the elevated plus maze [72].

Sudati et al. studied the protective effect of $V$. officinalis on LPO induced by different pro-oxidant agents with neuropathological importance. Ethanolic extract of valerian $(0-60 \mu \mathrm{g} / \mathrm{ml})$ was tested against quinolinic acid $(\mathrm{QA}), 3$-nitropropionic acid, sodium nitroprusside, and iron sulfate $\left(\mathrm{FeSO}_{4}\right)$ and $\mathrm{Fe}^{+} /$EDTA induced LPO in rat brain homogenates. The effect of $V$. officinalis in deoxyribose degradation and reactive oxygen species production were also investigated. The result suggested that $V$. officinalis extract was effective in modulating LPO induced by different pro-oxidant agents and because of that $V$. officinalis extract, functioning as an antioxidant agent, can be beneficial for reducing insomnia complications linked to oxidative stress [73]. Fachinetto et al. examined the effects of $V$. officinalis, a medicinal herb widely used as calming and sleep-promoting, in an animal model of orofacial dyskinesia induced by long-term treatment with haloperidol. Parameters such as VCMs, locomotor activity and plus maze performance were evaluated. Treatment with haloperidol and/ or $V$. officinalis decreased the locomotor activity in the open field test. They determined that haloperidol treatment significantly decreased $[3 \mathrm{H}]$-dopamine uptake in striatal slices and $V$. officinalis was not able to prevent this effect [74]. Malva et al. evaluated the neuroprotective effects of $V$. officinalis against the toxicity induced by amyloid beta 
<smiles>CC1=C2[C@H](/C=C(\C)C(=O)O)CC[C@H](C)[C@]2(C)CC1</smiles>

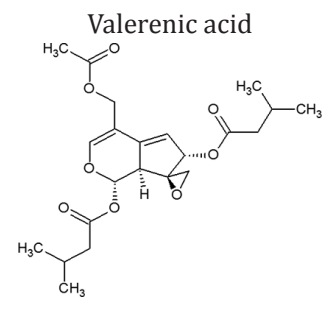<smiles>CC(=O)OC[C@]12CC3C(C=O)C=C[C@@H]4[C@H]([C@H]3C[C@H]1O2)C4(C)C</smiles>

Volvalerenal A

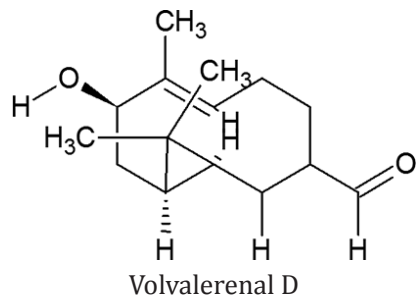<smiles>C=C1C(O)CCC2=CC3C4(O)C[C@@H](C12C4)C3(C)C</smiles>

Volvalerenic acid C

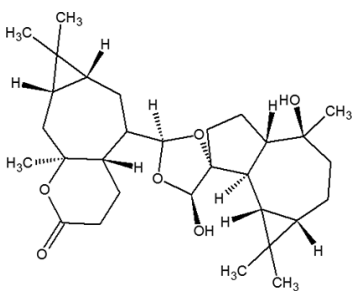

Volvalerelactone B

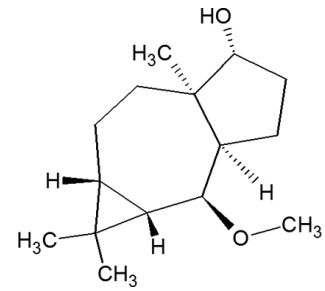

Valeneomerin C<smiles>CC(C)[C@@H]1CC[C@@]2(C)CCCC(=O)[C@@]2(C)C1</smiles>

Valeranone

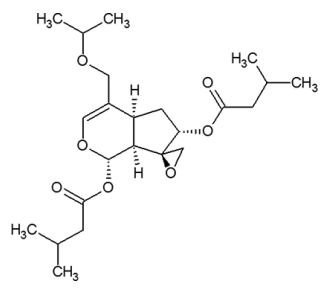

Didrovaltrate

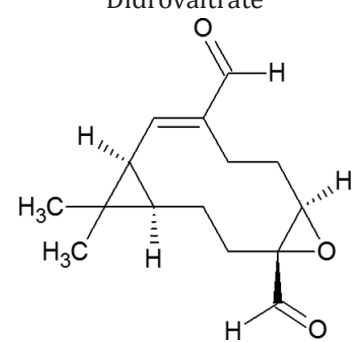

Volvalerenal B

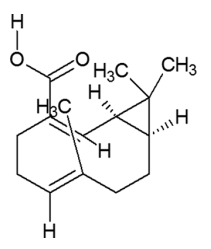

Volvalerenic acid A

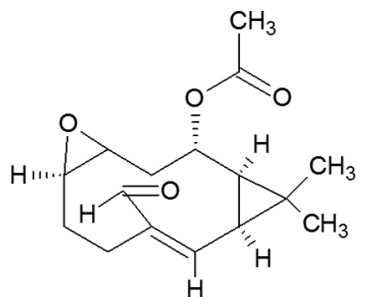

Volvalerenal C

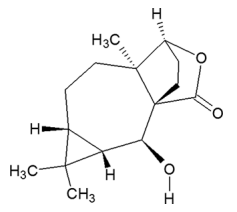

Valeneomerin A

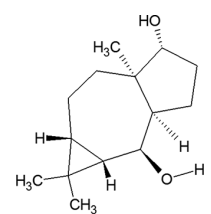

Valeneomerin D
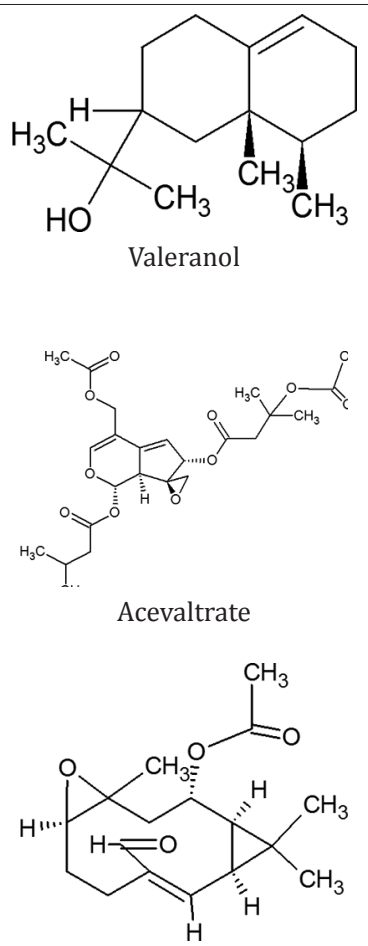

Volvalerenal C

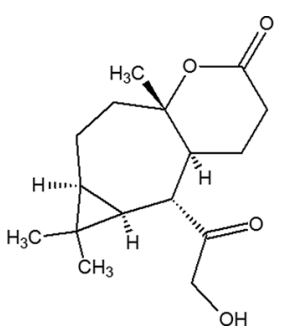

Volvalerenic acid B

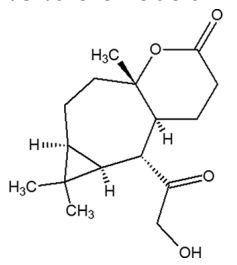

Olvalerelactone A

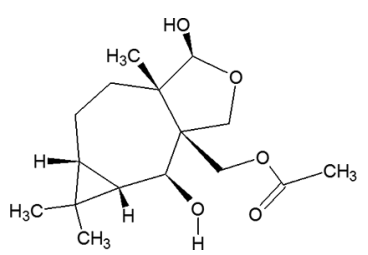

Valeneomerin B

Fig. 2: Chemical constituents of Valeriana officinalis [23-29] 
peptide 25-35 (Aß $\left.\beta^{25-35)}\right)$. Cultured rat hippocampal neurons were exposed to $A \beta_{(25-35)}(25 \mu \mathrm{M})$ for $24-48 \mathrm{~h}$, after which morphological and biochemical properties were evaluated. The neuronal injury (decrease in cell reducing capacity and associated neuronal degeneration) evoked by $A ß$, and prevented by valerian extract. From the study, it concluded that the signaling pathways involving $[\mathrm{Ca} 2+]_{i}$ and the redox state of the cells may play a central role in the neuroprotective properties of V. officinalis extract against $A ß$ toxicity [10].

\section{CYTOPROTECTIVE EFFECTS}

The potential cytoprotective effects of aqueous extract of $V$. officinalis on rotenone-induced apoptosis inhuman neuroblastoma SH-SY5Y cells were demonstrated by de Oliveria et al. The cytotoxicity, cell viability and analysis of cellular morphology were performed by MTT assay and phase contrast microscopy. Significant changes in the cellular morphology and condensation of the cell body could be observed when cells were treated with $300 \mathrm{nM}$ rotenone for $48 \mathrm{~h}$. The results indicated that neuroprotective action of the $V$. officinalis extracts support for the development of the cytoprotective drug in various therapies [75]. Do et al. evaluated pinoresinol-4,40-di-O-b-D-glucoside (PDG) from $V$. officinalis induced calcium mobilization and cell migration through the activation of lysophosphatidic acid (LPA) receptor subtypes. PDGinduced MEF cell migration was attenuated by pretreatment with aphosphatidylinositol3-kinase (PI3K) inhibitor such as LY294002. Cells lacking downstream mediator of PI3K such as Akt1 and Akt2 (DKO cells) showed loss of PDG-induced migration. They concluded that PDG is a strong inducer of cell migration and the pharmacological action of PDG may occur through the activation of an LPA receptor whereby activation of PI3K/Akt signaling pathway mediates PDG-induced MEF cell migration [76].

\section{ANTI CORONARY SPASTIC/ANTIBRONCHOSPASTIC ACTIVITY}

Circosta et al. were investigated anti coronary spastic, and antibronchospastic activities of ethanolic and aqueous extracts of Valeriana officinalis roots in anesthetized guinea-pigs, and the results were correlated with the qualitative/quantitative chemical composition of the extracts. Protective effects were evaluated for orally administered ethanolic and aqueous extracts (50, 100, and $200 \mathrm{mg} / \mathrm{kg}$ ) against Pitressin-induced coronary spasm and pressor response in guinea-pigs and were compared with those of nifedipine. The protective effects against histamine-induced and Oleaceae antigen challenge induced bronchospasm were also evaluated. The results showed that two valeriana extracts possessed significant anti coronary spastic, antihypertensive, and antibronchospastic properties. This study justified the traditional use of this plant in the treatment of some respiratory and cardiovascular disorders [77].

\section{CONCLUSION}

V. officinalis is endemic to many parts of Europe, Asia and North America and are widely used in traditional medicine for various applications. $V$. officinalis, on its own or as part of a polyherbal preparation is a valuable remedy for cancer and neuroprotective disorders. The phytochemical results have indicated a variety of chemical constituents. Pharmacological studies indicated that these plants possessed various biological activities, especially in the areas of antioxidant, anti-inflammatory, anticancer, anticonvulsive, anti-Parkinson's and anti-Alzheimer's disease, etc. Regarding the constituents contributed to therapeutic values, the findings indicated that Valepotriates are major components for the treatment of epilepsy, depressant, Parkinson's disease, and Alzheimer's disease. Although great progress on the phytochemistry and pharmacology of $V$. officinalis have been made, there still need more conclusive studies on the safety, efficacy and in vivo toxicity of extracts and pure compounds to gain a better understanding. Collectively, this present review provides systematical information on the ethnopharmacology, phytochemistry, and pharmacology of $V$. officinalis, which supports the further clinical use in modern medicine.

\section{REFERENCES}

1. Grieve M. In: Leyel CF, editor. A Modern Herbal. London: Tiger Books International; 1976. p. 912.

2. Hobbs C. Valerian monograph. Herbal Gram 1989;21:19-34.

3. Benigni R, Capra C, Cattorini P. Piante Medicinali Chimica Farmacologia E Terapia. Vol. 1. Milano: Inverni \& Della Beffa; 1971. p. 730 .

4. King J. The American Dispensatory. $7^{\text {th }}$ ed. Cincinnati: Moore, Wilstach \& Baldwin; 1866. p. 1509.

5. Ellingwood F, Lloyd JU. A Systematic Treatise on Materia Medica and Therapeutics. Chicago: Chicago Med Press; 1900. p. 706.

6. Scudder JM. Specific Medications and Specific Medicines. $15^{\text {th }}$ ed. Cincinnati: Scudder Bros; 1903, 1985. p. 432.

7. Arshad HR, Yousef HA. Potential role of Carica papaya and their active constituents in the prevention and treatment of diseases. Int $\mathrm{J}$ Pharm Pharm Sci 2016;8:11-5.

8. Fleming T. PDR for Herbal Medicines. Montvale, NJ: Medical Economics Company, Inc.; 1998.

9. Stevinson C, Ernst E. Valerian for insomnia: A systematic review of randomized clinical trials. Sleep Med 2000;1:91-9.

10. Malva JO, Santos S, Macedo T. Neuroprotective properties of Valeriana officinalis extracts. Neurotox Res 2004;6:131-40.

11. Diaper A, Hindmarch I. A double-blind, placebo-controlled investigation of the effects of two doses of a valerian preparation on the sleep, cognitive and psychomotor function of sleep-disturbed older adults. Phytother Res 2004;18:831-6.

12. Houghton PJ. The scientific basis for the reputed activity of Valerian. J Pharm Pharmacol 1999;51:505-12.

13. Council of Scientific and Industrial Research. Valeriana officinalis Linn. The Wealth of India: A Dictionary of Indian Materials and Industrial Products. Vol. 9. New Delhi: Council of Scientific and Industrial Research; 2009. p. 426.

14. Andrews MJ, Basu A. US Patent No. 6913770 B2; 2005.

15. Straube G. The importance of valerian roots in therapy. Ther Ggw 1968; 107:555-62.

16. Valerian (Herb). Wikipedia, the Free Encyclopedia. Available from: https://www.en.wikipedia.org/wiki/Valerian(herb).

17. Valerian (Valeriana officinalis) Overview, Health Benefits, Side Effects. Available from: http://www.tipdisease.com/2015/11/valerianvaleriana-officinalis-overview.html.

18. Valeriana officinalis Encyclopedia on Indian Medicinal Plants. Available from: http://www.envis.frlht.org/bot_search.php.

19. Khare CP. Indian Medicinal Plants: An Illustrated Dictionary. New York: Springer; 2007. p. 692

20. Newall CA, Anderson LA, Phillipson JD. Herbal Medicines: A Guide for Health-Care Professionals. London: The Pharmaceutical Press; 1996.

21. Bissett NG. Herbal Drugs and Phytopharmaceuticals. Stuttgart: Med Pharm CRC Press; 1994. p. 566.

22. Marder M, Viola H, Wasowski C, Fernández S, Medina JH, Paladini AC 6-methylapigenin and hesperidin: New valeriana flavonoids with activity on the CNS. Pharmacol Biochem Behav 2003;75:537-45.

23. Khom S, Baburin I, Timin E, Hohaus A, Trauner G, Kopp B, et al. Valerenic acid potentiates and inhibits $\operatorname{GABA}(\mathrm{A})$ receptors: Molecular mechanism and subunit specificity. Neuropharmacology 2007;53:178-87.

24. Benke D, Barberis A, Kopp S, Altmann KH, Schubiger M, Vogt KE, et al. GABA A receptors as in vivo substrate for the anxiolytic action of valerenic acid, a major constituent of valerian root extracts. Neuropharmacology 2009;56:174-81.

25. Goppel M, Franz G. Stability control of valerian ground material and extracts: A new HPLC-method for the routine quantification of valerenic acids and lignans. Pharmazie 2004;59:446-52.

26. Wang PC, Ran XH, Chen R, Luo HR, Liu YQ, Zhou J, et al. Germacranetype sesquiterpenoids from the roots of Valeriana officinalis var. latifolia. J Nat Prod 2010;73:1563-7.

27. Chavadej S, Becker H, Weberling F. Further investigations of valepotriates in the Valerianaceae. Pharm Weekbl Sci 1985;7:167-8.

28. Wagner H, Schaette R, Hörhammer L, Hölzl J. Dependence of the valepotriate and essential oil content in Valeriana officinalis L.s.l. on various exogenous and endogenous factors. Arzneimittelforschung 1972;22:1204-9.

29. Wang PC, Ran XH, Luo HR, Hu JM, Chen R, Ma QY, et al. Volvalerelactones A and B, two new sesquiterpenoid lactones with an unprecedented skeleton from Valeriana officinalis var. Latifolia. Org Lett 2011;13:3036-9.

30. Chen HW, Chen L, Li B, Yin HL, Tian Y, Wang Q, et al. Three new 
germacrane-type sesquiterpenes with NGF-potentiating activity from Valeriana officinalis var. Latiofolia. Molecules 2013;18:14138-47.

31. Han ZZ, Zu XP, Wang JX, Li HL, Chen BY, Liu QX, et al. Neomeranetype sesquiterpenoids from Valeriana officinalis var. Latifolia. Tetrahedron 2014;70:962-6.

32. Oshima Y, Matsuoka S, Ohizumi Y. Antidepressant principles of Valeriana fauriei roots. Chem Pharm Bull (Tokyo)1995;43:169-70.

33. Jia JN, Zhang BH. Effect of valerian extract (V3d) on cardiovascular system [J]. J Guangxi Coll Tradit Chin Med 1999;16:40-2.

34. Becker H, Chavadej S. Valepotriate production of normal and colchicine-treated cell suspension cultures of Valeriana wallichii. J Nat Prod 1985;48:17-21.

35. McCabe S. Complementary herbal and alternative drugs in clinical practice. Perspect Psychiatr Care 2002;38:98-107.

36. Nithya S, Sundaram MM. An overview on the biological perspectives of Nardostachys jatamansi. Int J Pharm Pharm Sci 2016;8:31-6.

37. Morazzoni P, Bombardelli E. Valeriana officinalis: Traditional use and recent evaluation of activity. Fitoterapia 1995;66:99-112.

38. Miguel H, Feistel B, Hartwig S, Romanus L, Mirjam H, Hilke W. Extracts of Valeriana officinalis L. S.L. show anxiolytic and antidepressant effects but neither sedative nor myorelaxant properties. Phytomedicine 2008;15:2-15.

39. Hazelhoff B, Malingré TM, Meijer DK. Antispasmodic effects of valeriana compounds: An in-vivo and in-vitro study on the guinea-pig ileum. Arch Int Pharmacodyn Ther 1982;257:274-87.

40. Murakami N, Ye Y, Kawanishi M, Aoki S, Kudo N, Yoshida M, et al. New rev-transport inhibitor with anti-HIV activity from Valerianae Radix. Bioorg Med Chem Lett 2002;12:2807-10.

41. Carlini EA. Plants and the central nervous system. Pharmacol Biochem Behav 2003;75:501-12.

42. Hendriks H, Bos R, Allersma DP, Malingré TM, Koster AS. Pharmacological screening of valerenal and some other components of essential oil of Valeriana officinalis. Planta Med 1981;42:62-8.

43. Wang PC, Ran XH, Luo HR, Ma QY, Zhou J, Hu JM, et al. Volvalerine A, an unprecedented $\mathrm{N}$-containing sesquiterpenoid dimer derivative from Valeriana officinalis var. Latifolia. Fitoterapia 2016;109:174-8.

44. Mirzaei M, Dinpanah H. Three phases hollow fiber LPME combined with HPLC-UV for extraction, preconcentration and determination of valerenic acid in Valeriana officinalis. J Chromatogr B Analyt Technol Biomed Life Sci 2011;879:1870-4

45. Wang PC, Ran XH, Chen R, Li LC, Xiong SS, Liu YQ, et al. Volvalerenone a, a new type of mononorsesquiterpenoid with an unprecedented 3, 12-oxo bridge from Valeriana officinalis. Tetrahedron Lett 2010;51:5451-3

46. Ying ZH, Ying FA, Zhan-Feng GO, Xue-Yun DU, Yan-Wen LI. Two new terpenoids from Valeriana officinalis. Chin J Nat Med 2009;7:270-3.

47. Wills RB, Shohet D. Changes in valerenic acids content of valerian root (Valeriana officinalis L. SL.) during long-term storage. Food Chem 2009; $115: 250-3$

48. Safaralie A, Fatemi S, Sefidkon F. Essential oil composition of Valeriana officinalis L. roots cultivated in Iran. Comparative analysis between supercritical $\mathrm{CO} 2$ extraction and hydrodistillation. J Chromatogr A 2008;1180:159-64.

49. Huang B, Qin L, Chu Q, Zhang Q, Gao L, Zheng H. Comparison of headspace SPME with hydrodistillation and SFE for analysis of the volatile components of the roots of Valeriana officinalis var. Latifolia. Chromatographia 2009;69:489.

50. Hromádková Z, Ebringerová A, Valachovic P. Ultrasound-assisted extraction of water-soluble polysaccharides from the roots of valerian (Valeriana officinalis L.). Ultrason Sonochem 2002;9:37-44.

51. Paul C, König WA, Muhle H. Pacifigorgianes and tamariscene as constituents of Frullania tamarisci and Valeriana officinalis. Phytochemistry 2001;57:307-13.

52. Tori M, Yoshida M, Yokoyama M, Asakawa Y. A guaiane-type sesquiterpene, valeracetate from Valeriana officinalis. Phytochemistry 1996;41:977-9.

53. Gränicher F, Christen P, Kapetanidis I. Essential oils from normal and hairy roots of Valeriana officinalis var. Sambucifolia. Phytochemistry 1995;40:1421-4.

54. Gränicher F, Christen P, Kamalaprija P, Burger U. An iridoiddiester from Valeriana officinalis var. Sambucifolia hairy roots. Phytochemistry 1995;38:103-5.

55. Lokar LC, Moneghini M. Geographical variation in the monoterpenes of Valeriana officinalis Leaf. Biochem Syst Ecol 1989;17:563-7.
56. Bos R, Hendriks H, Bruins AP, Kloosterman J, Sipma G. Isolation and identification of valerenane sesquiterpenoids from Valeriana officinalis. Phytochemistry 1985;25:133-5.

57. Bos R, Hendriks H, Kloosterman J, Sipma G. A structure of faurinone, a sesquiterpene ketone isolated from Valeriana officinalis. Phytochemistry 1983;22:1505-6.

58. Hendriks H, Geertsma HJ, Malingré TM. The occurrence of valeranone and crypto-fauronol in the essential oil of Valeriana officinalis L. SL collected in the northern part of the Netherlands. Pharm World Sci 1981;3:1316-20

59. Hazelhoff B, Weert B, Denee R, Malingré TM. Isolation and analytical aspects of Valeriana compounds. Pharm World Sci 1979;1:956-64.

60. Hazelhoff B, Smith D, Malingré TM, Hendriks H. The essential oil of Valeriana officinalisL. SL. Pharm World Sci 1979;1:443-9.

61. Popov S, Handjieva N, Marekov N. A new valepotriate: 7-epideacetylisovaltrate from Valeriana officinalis. Phytochemistry 1974;13:2815-8.

62. Johnson RD, Waller GR. Isolation of actinidine from Valeriana officinalis. Phytochemistry 1971;10:3334-5.

63. Torssell R, Wahlberg K. The structure of the principal alkaloid from Valeriana officinalis (L.). Tetrahedron Lett 1966;7:445-8.

64. Chen HW, He XH, Yuan R, Wei BJ, Chen Z, Dong JX, et al. Sesquiterpenes and a monoterpenoid with acetylcholinesterase (AchE) inhibitory activity from Valeriana officinalis var. latiofolia in vitro and in vivo. Fitoterapia 2016;110:142-9.

65. Torres-Hernández BA, Del Valle-Mojica LM, Ortíz JG. Valerenic acid and Valeriana officinalis extracts delay onset of pentylenetetrazole (PTZ)-induced seizures in adult Danio rerio (Zebrafish). BMC Complement Altern Med 2015;15:228

66. Nam SM, Choi JH, Yoo DY, Kim W, Jung HY, Kim JW, et al. Valeriana officinalis extract and its main component, valerenic acid, ameliorate D-galactose-induced reductions in memory, cell proliferation, and neuroblast differentiation by reducing corticosterone levels and lipid peroxidation. Exp Gerontol 2013;48:1369-77.

67. Shahidi S, Bathaei A, Pahlevani P. Antinociceptive effects of Valeriana extract in mice: Involvement of the dopaminergic and serotonergic systems. Neurophysiology 2013;45:448-52.

68. Sudati JH, Vieira FA, Pavin SS, Dias GR, Seeger RL, Golombieski R, et al. Valeriana officinalis attenuates the rotenone-induced toxicity in Drosophila melanogaster. Neurotoxicology 2013;37:118-26.

69. Pereira RP, Fachinetto R, de Souza Prestes A, Wagner C, Sudati JH, Boligon AA, et al. Valeriana officinalis ameliorates vacuous chewing movements induced by reserpine in rats. J Neural Transm (Vienna)2011;118:1547-57.

70. Barton DL, Atherton PJ, Bauer BA, Moore DF Jr, Mattar BI, Lavasseur BI, et al. The use of Valeriana officinalis (Valerian) in improving sleep in patients who are undergoing treatment for cancer: A phase III randomized, placebo-controlled, double-blind study (NCCTG Trial, N01C5). J Support Oncol 2011;9:24-31.

71. Rezvani ME, Roohbakhsh A, Allahtavakoli M, Shamsizadeh A. Anticonvulsant effect of aqueous extract of Valeriana officinalis in amygdala-kindled rats: Possible involvement of adenosine. J Ethnopharmacol 2010;127:313-8.

72. Murphy K, Kubin ZJ, Shepherd JN, Ettinger RH. Valeriana officinalis root extracts have potent anxiolytic effects in laboratory rats. Phytomedicine 2010;17:674-8.

73. SudatiJH, Fachinetto R, Pereira RP, BoligonAA, Athayde ML, Soares FA, et al. In vitro antioxidant activity of Valeriana officinalis against different neurotoxic agents. Neurochem Res 2009;34:1372-9.

74. Fachinetto R, Villarinho JG, Wagner C, Pereira RP, Avila DS, Burger ME, et al. Valeriana officinalis does not alter the orofacial dyskinesia induced by haloperidol in rats: Role of dopamine transporter. Prog Neuropsychopharmacol Biol Psychiatry 2007;31:1478-86.

75. de Oliveria DM, Barreto G, De Andrade DV, Saraceno E, Aon-Bertolino L, Capani F, et al. Cytoprotective effect of Valeriana officinalis extract on an in vitro experimental model of Parkinson disease. Neurochem Res 2009;34:215-20

76. Do KH, Choi YW, Kim EK, Yun SJ, Kim MS, Lee SY, et al. Pinoresinol4,4'-di-O-beta-D-glucoside from Valeriana officinalis root stimulates calcium mobilization and chemotactic migration of mouse embryo fibroblasts. Phytomedicine 2009;16:530-7.

77. Circosta C, De Pasquale R, Samperi S, Pino A, Occhiuto F. Biological and analytical characterization of two extracts from Valeriana officinalis. J Ethnopharmacol 2007;112:361-7. 